\title{
Case Report: Multilocular Type of Mandibular Simple Bone Cyst. Part 1: Cone Beam Computed Tomography (CBCT) Findings, Revision of the Synonyms and Treatment Strategies*
}

\author{
Oleksandr A. Nozhenko ${ }^{1, *}$, Valentyna I. Zaritska ${ }^{2}$, Pavlo P. Snisarevskyil, and levgen I. Fesenko ${ }^{4}$ \\ ${ }^{1}$ Center of Maxillofacial Surgery, Kyiv Regional Clinical Hospital, Kyiv, Ukraine (Maxillofacial Surgeon) \\ ${ }^{2}$ Associate Professor, Department of Pathology, Shupyk National Medical Academy of Postgraduate Education, Kyiv, Ukraine $(P h D)$ \\ ${ }^{3}$ Head, Department of Pathomorphology, Kyiv Regional Clinical Hospital, Kyiv, Ukraine \\ ${ }^{4}$ Assistant Professor, Department of Oral and Maxillofacial Surgery, Private Higher Educational Establishment "Kyiv Medical University", Kyiv, \\ Ukraine $(P h D)$
}

\section{ABOUT ARTICLE}

\section{Article history:}

Paper received 03 April 2018

Accepted 10 June 2018

Available online 25 December 2018

Keywords:

Simple bone cyst (SBC)

Solitary bone cyst

Traumatic bone cyst

Unilocular bone cyst

Unilocular type of simple bone cyst

Multilocular type of simple bone cyst

\begin{abstract}
SUM M A RY
Simple bone cyst (SBC) is an intraosseous pseudocyst without epithelial lining [1]. The purpose of our report is to demonstrate case of a multilocular type of mandibular simple bone cyst. The precise consecutive cone beam computed tomography (CBCT) scans and a CT result of biopsy are presented. Revision of wide range of synonyms and a treatment options for multilocular (synonym: multicameral) type of SBCs are presented.
\end{abstract}

( 2018 OMF Publishing, LLC. This is an open access article under the CC BY licence (http://creativecommons.org/licenses/by-nc/4.0/).

\section{Introduction}

Simple bone cyst (SBC) is an intraosseous pseudocyst without epithelial lining [1]. Internationally known 7 synonyms of the SBC are solitary bone cyst, traumatic bone cyst, hemorrhagic bone cyst, hemorrhagic cyst, idiopathic bone cavity, unicameral bone cyst and bone cyst without lining $[2,3]$. Some authors from oral and maxillofacial surgery advocates that correct name of that pseudocyst is solitary bone cyst [3], others - for the name idiopathic bone cavity [4]. In the orthopedic literature, these lesions are commonly termed simple bone cysts or unicameral cysts $[4,5]$. The World Health Organization in 2012 that type of a non-neoplastic intraosseous pseudocyst devoid of epithelial lining named as simple bone cyst [4, 6]. The purpose of our report is to demonstrate case of

\footnotetext{
* This manuscript has not been presented

* Corresponding author. Center of Maxillofacial Surgery, Kyiv Regional Clinical Hospital,

1 Bahhovutivska Street, Kyiv 04107, Ukraine.

Tel.: +38 (067) 2319274.

E-mail address: alexdent@ukr.net (Oleksandr A. Nozhenko)

E-mails of the co-authors:

viomelvi@gmail.com (Valentyna I. Zaritska)

sneip78@gmail.com (Pavlo P. Snisarevskyi)

i.i.fesenko@dtjournal.org (levgen I. Fesenko)

http://dx.doi.org/10.23999/j.dtomp.2018.4.6
}

a multilocular type of mandibular simple bone cyst. The precise consecutive cone beam computed tomography (CBCT) scans and a CT result of biopsy are presented. New term criteria and a treatment option for multilocular (synonym: multicameral) type of SBCs are proposed.

\section{Case Report}

A 41-year-old white lady was referred to the Center of Maxillofacial Surgery (Kyiv Regional Clinical Hospital) according to incedenticaly finding at panoramic radiography of an asymptomatic lesion of right mandible. Cone beam computed tomography (CBCT) showed a well-circumscribed translucent multilocular lesion, measuring $41 \times 10.08 \times 16.42 \mathrm{~mm}$ (Fig 1 ) without bony expansion/destruction of the buccal/lingual cortical plates of the mandible. Complete septa is divided a cystic lesion into two cameras (Fig 2): anterior $(14.94 \times 7.71$ $\times 11.06)$ and posterior $(23.72 \times 11 \times 11.4)$. The roots of the teeth \#48-45 located inside the lesion. Noted no roots resorption or displacement of the teeth involved into both cystic cameras. Tooth \#46 was endodontically treated several years ago according to medical history and has periapical lesions at both roots. According to the patients' words she did not notice any previous trauma. Paresthesia of the lower lip was absent. The pulp vitality 
test (Vitality Scanner 2006, SybronEndo, Glendora, CA, USA) showed pulp response in the teeth \#45, 47, and 48. The biopsy procedure was performed under local anesthesia (2.2 $\mathrm{ml}$ Ultracain D-S forte, Aventis Pharma Deutschland GmbH, Frankfurt, Germany). A $1.0 \mathrm{ml}$ of serous fluid was obtained after trepanation of buccal cortical plate. Upon careful curettage no lining was fined and the biopsy specimen included small amount of trabecular bone. Pathology specimen showed blood clots in the huge areas of fibrous tissue and collagen.
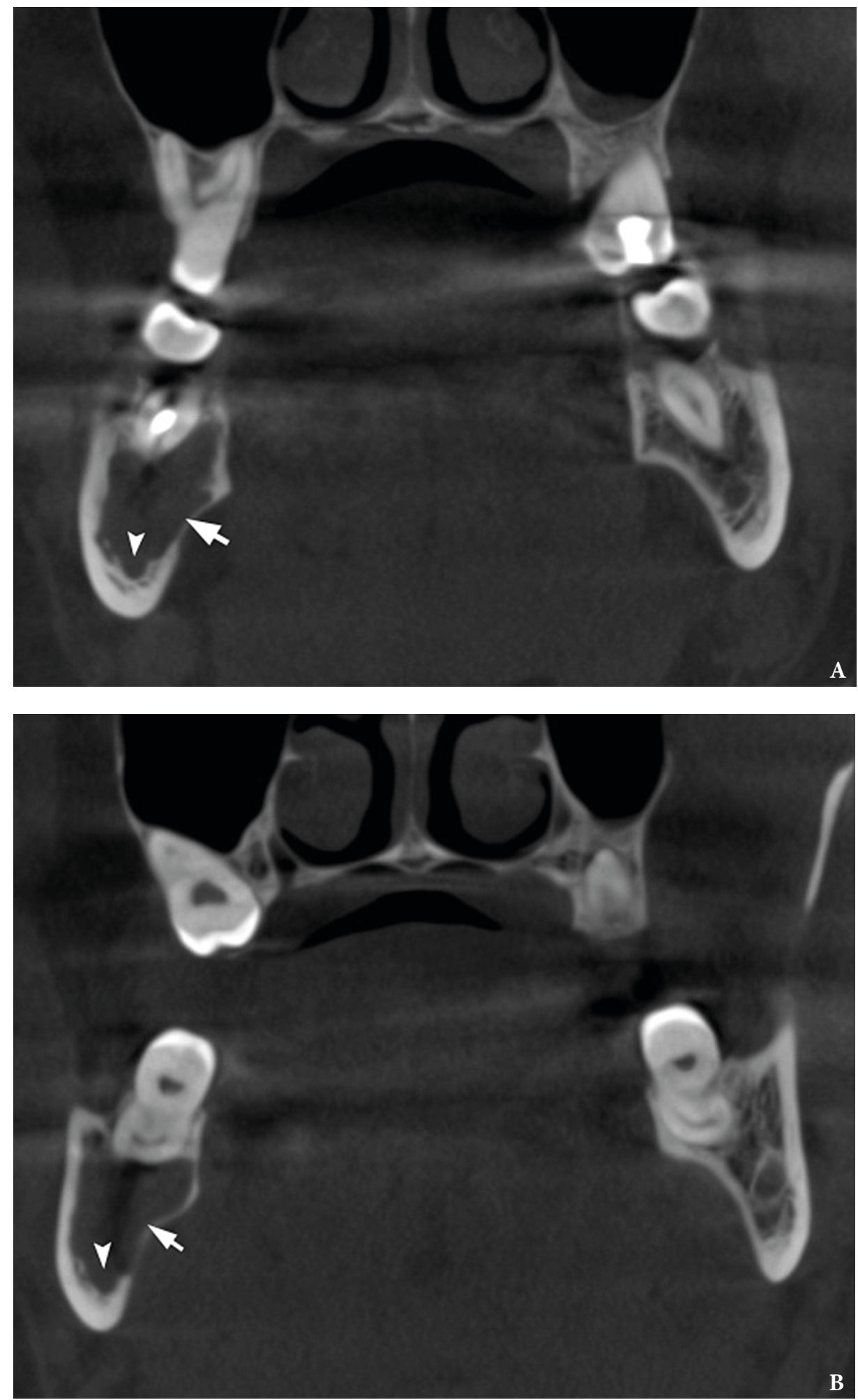

FIGURE 1. Cone beam computed tomography (CBCT). (A) Coronal scan at the level of teeth \#46, 47 on the right and teeth \#36, 37 on the left. Simple bone cyst is indicated by arrow. The neurovascular bundle (arrowhead) is pushed towards the inferior border of mandibular body. (B) Coronal scan at the level of tooth \#48 on the right and tooth \#38 on the left. 
A pathology diagnosis of a simple bone cyst was established. Fulfillment with blood clot only an anterior camera was confirmed by CT ( 5 months after the biopsy) showing its ossification (Fig 3). It's evidence of that anterior and posterior camera was not communicated.
Also, it's evidence of that in case of completely separate cameras the minimally invasive interventions on both cystic cameras should be performed. A 2 years followup shows no recurrence of the lesion and complains from the patient.
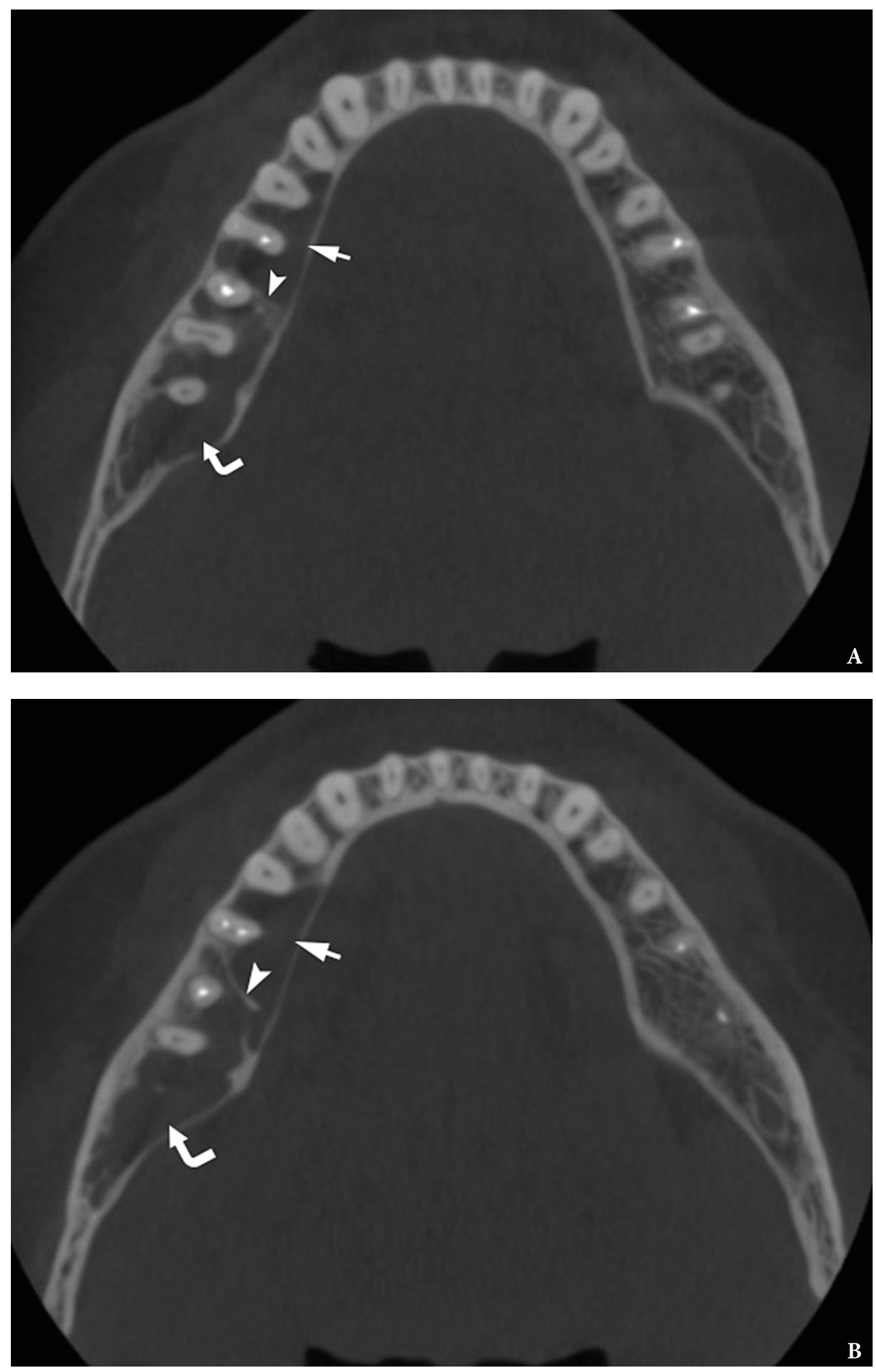

FIGURE 2. Cone beam computed tomography (CBCT). Axial scan at the level of upper parts (A) and middle parts (B) of roots of the teeth \#45-47. Anterior camera of simple bone cyst is indicated by straight arrow, posterior camera - by curved arrow, intracystic septa - by arrowhead. (Fig 2 continued on next page.) 
NOZHENKO ETAL
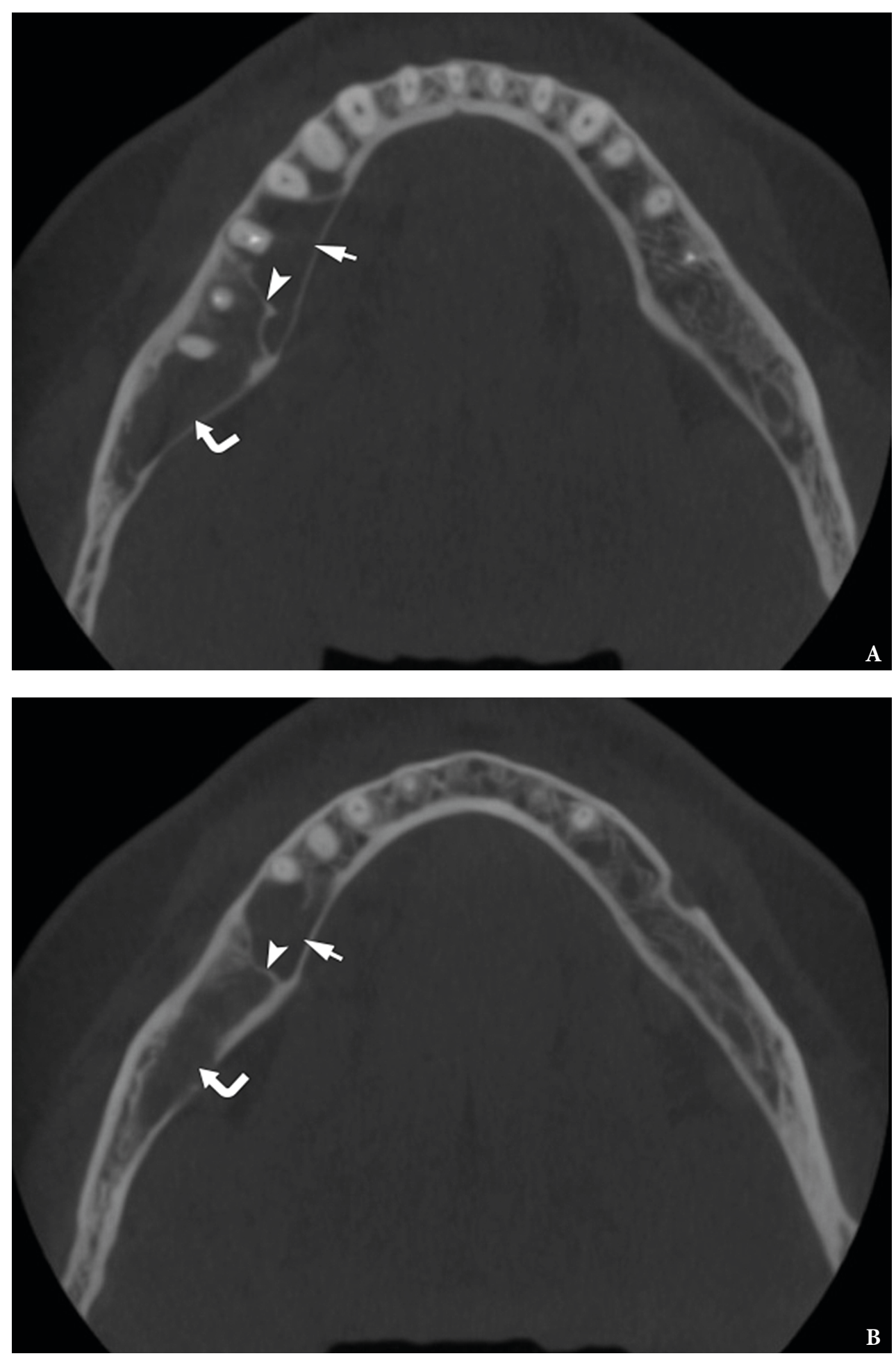

FIGURE 2. (cont'd). Axial scan at the level of lower parts (C) and below the (D) of roots of the teeth \#45-47. Anterior camera of simple bone cyst is indicated by straight arrow, posterior camera - by curved arrow, intracystic septa - by arrowhead. 


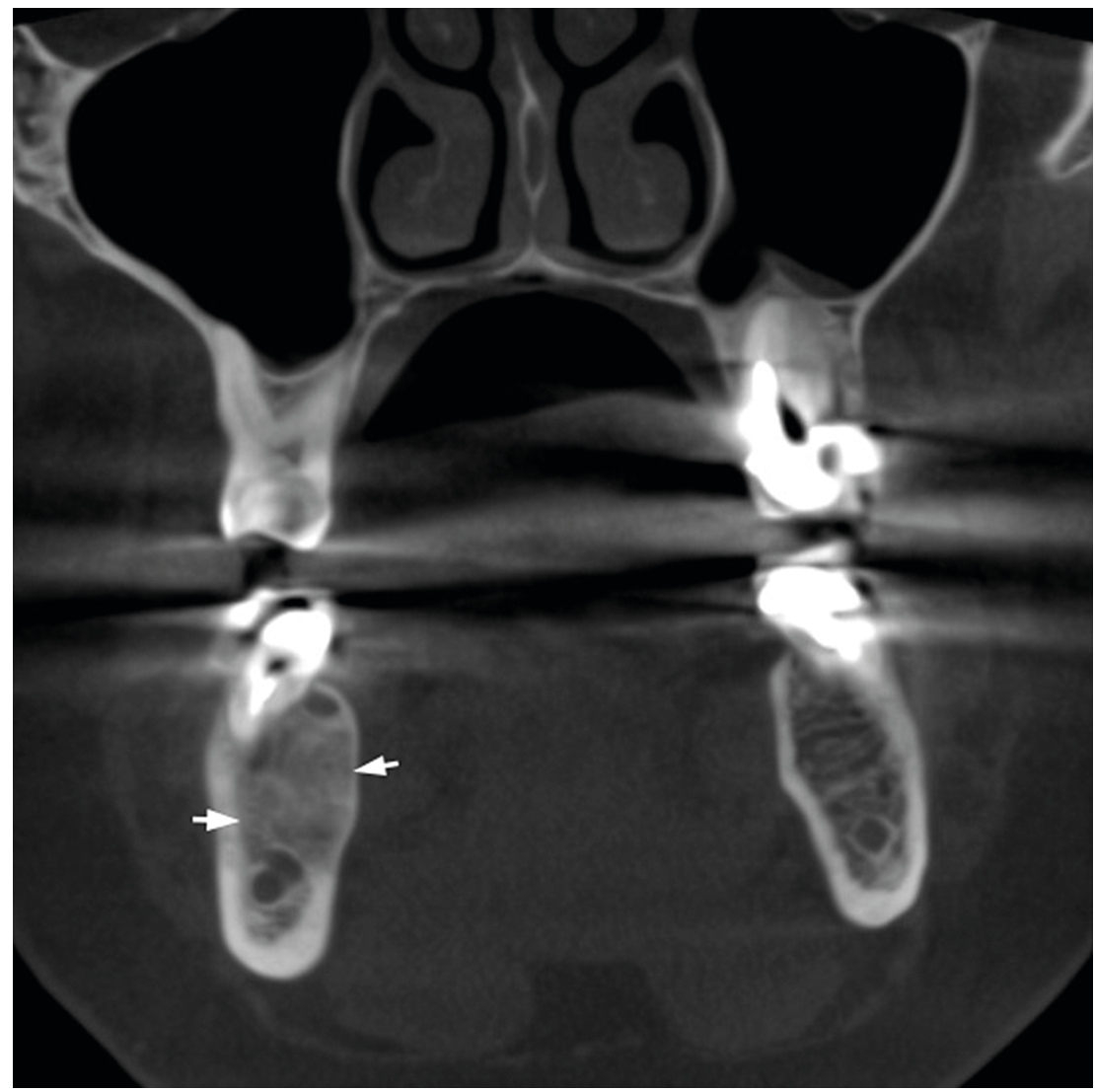

FIGURE 3. CBCT coronal scan 5 months after biopsy (minimally invasive perforation the buccal cortical bone and curettage with stimulation of blood clot formation) at the level of tooth \#46 (projection of anterior camera of SBC). Noted a complete fulfillment only the anterior cystic camera (in which biopsy was performed) with a bone (range from $16 \mathrm{HU}$ to $362 \mathrm{HU}$ ) that is denser than on the contralateral site (range from -235 HU to 204 HU).

\section{Discussion}

According to different authors (Strabbing et al, 2011; Tymofieiev, 2012; Resnick et al, 2016) the differential diagnosis included odontogenic keratocyst, odontogenic tumor (odontogenic myxoma, unicystic or multicystic ameloblastoma), giant cell granuloma, aneurysmal bone cyst [2-4]. Flores et al (2017) made a unique comparison SBCs and aneurysmal bone cysts [7]. According to their review aneurysmal bone cysts tends to have more aggressive clinical behavior than SBC [7]. Stephanie J. Drew, DMD (Founding Editor-in-Chief of Oral and Maxillofacial Surgery Cases) reported in the paper of Choi et al (2011) precise description of aneurysmal bone cysts [8]. According to their article the World Health Organization definition of those cysts is an expansive osteolytic lesion, identified histologically, that consists of blood-filled spaces and canals divided by connective tissue septa that can contain osteoid tissue and osteoclastlike giant cells [8].

Despite the fact of wide range of differential diagnosis a first diagnosis that our patient received in other clinic was an ameloblastoma. What was rejected by our team and proved the diagnosis of SBC (multilocular type) by the biopsy (Fig 3).

\section{COMPUTED TOMOGRAPHY (CT) AND PANORAMIC RADIOGRAPHY FEATURES OF SBC}

Panoramic radiograph typically shows translucent unilocular/multilocular images (Martins-Filho et al, 2012) [9]. Images corresponding to 21 cases of CortellBallester et al (2009) did not differ significantly from the classical descriptions: radiotransparencies of variable size and shape, sometimes appearing between the dental roots [10]. No displacement or resorption of teeth (Larheim and Westesson, 2018) are founded in the area of SBCs [11]. Imanimoghaddam et al (2011) fixed that simple bone cysts may seem multilocular occasionally in spite of not having septa which is due to the propensity of the lesion to scallop the endosteal surface of the outer cortex of the mandible [12]. From the 26 cases reported by MartinsFilho et al (2012) 19 cases (73.1\%) were unilocular, 7 cases were multilocular (26.9\%) [9]. In the study of Resnick et al (2016) SBCs were unilocular in 44 cases (in 93.62\%) or multilocular in 3 cases (in 6.38\%) [4]. Our case confirms the existence of multilocular type of simple bone cysts. That pattern of SNC: 1) refutes the term unicameral bone cyst as a synonym of that type of lesion in jaws; 2) can require (in case of complete intracystic septa) a minimally invasive intervention on both cameras. 


\section{MAGNETIC RESONANCE IMAGING (MRI) FEATURES OF SBC}

Larheim and Westesson (2018) reported that at T1weighted MRI SBCs - homogeneous intermediate signal, at T2-weighted and STIR MRI - homogeneous high signal [11].

\section{TREATMENT OPTIONS FOR SBC}

Resnick et al (2016) lists six SBCs treatment tactics that are using in orthopedic surgery literature [4]:

1) Debridement;

2) Resection and rigid fixation;

3) Cryogenic therapy;

4) Corticosteroid injection;

5) Bone grafting;

6) Autologous bone marrow injection.

There are three the most popular treatment options for the SBCs that are using by maxillofacial and oral surgeons [1, 13, 14]:

1. Small size cortical bone perforation and stimulation of blood clot formation [1];

2. Careful curettage of the cavity, and flap repositioning and suture without any type of filler material [13];

3. Decompression (drainage fixation for 3 days) and warm saline solution irrigation [14].

Homem de Carvalho et al (2010) in their study confirms a success of treatment tactic that include a minimal bone intervention procedure to perforate the cortical bone and stimulate blood clot formation [1]. That type of treatment has two main advantages: the establishment of a definitive diagnosis and low invasiveness [1]. Fayzullina et al (2016) showed a successful treatment of SBC in the area of mandibular symphysis (near teeth \#44-33) using decompression technique [14]. The decompression method included next steps [14]: 1) $0.5 \mathrm{~cm}$ vertical incision at lower lip frenum; 2) $0.3 \mathrm{~cm}$ trepanation hole at cortical bone; 3) evacuation of the cystic liquid using aspiration; 4) curettage of cavity to receive biopsy material; 5) fixation a drainage; 6) irritation of the cystic cavity with warm saline solution during 2-3 days.

Serous content in the anterior camera of our case confirms existence of $3^{\text {rd }}$ type of SBC content which were established in a report of 26 cases (Martins-Filho et al, 2012) [9]: air was noted within the pathologic cavity in 18 cases $(69.2 \%)$, serous-bloody fluid in 5 cases (19.2\%), and serous fluid in 3 cases (11.6\%).

\section{RECCURENCE RATE}

Study of Suei et al (2007) proved in follow-up examination of 132 cases, greater than 20 percent of SBCs of the jaws recurred [15]. So, Imanimoghaddam et al (2011) insisted that clinical and radiological follow-up after SBCs surgery is strongly indicated [12].

\section{Conclusions}

So, precise CBCT description in our case of simple bone cyst with multilocular pattern confirms existence of multilocular variant of simple bone cyst. That fact requires revising a term unilocular bone cyst as a complete synonym of simple bone cyst. As the tem "unilocular" should be used only as description of one of two possible patterns of simple bone cysts. And minimally invasive interventions on both cystic cameras should be used as treatment option in case of multilocular pattern of SBC.

\section{Role of the Co-Authors}

Oleksandr A. Nozhenko (concept of the article, material collection, writing, and editing).

Valentyna I. Zaritska (material collection).

Pavlo P. Snisarevskyi (material collection).

Ievgen I. Fesenko (editing).

All authors read and approved the final manuscript.

\section{Term of Consent}

No needed.

Fundings

No funding was received for this study.

\section{Acknowledgments}

None.

\section{References}

1. Homem de Carvalho AL, Carrard VC, Martins MD, Rados PV, Filho MS. Simple bone cyst: report of cases and proposal for a minimal surgical intervention. Int $J$ Pediatr Otorhinolaryngol 2010;74(12):1449-51. https://doi. org/10.1016/j.ijporl.2010.09.014.

2. Tymofieiev OO. Manual of maxillofacial and oral surgery [in Russian]. 5th ed. Kyiv: Chervona Ruta-Turs; 2012.

3. Strabbing EM, Gortzak RA, Vinke JG, Saridin CP, van Merkesteyn JP. An atypical presentation of a solitary bone cyst of the mandibular ramus: a case report. $J$ Craniomaxillofac Surg 2011;39(2):145-7. https://doi. org/10.1016/j.jcms.2010.10.023.

4. Resnick CM, Dentino KM, Garza R, Padwa BL. A management strategy for idiopathic bone cavities of the jaws. J Oral Maxillofac Surg 2016;74(6):1153-8. https://doi. org/10.1016/j.joms.2015.12.014.

5. Coindre JM. New WHO classification of tumours of soft tissue and bone [in French]. Ann Pathol 2012;32(5):s115-6. https://doi.org/10.1016/j.annpat.2012.07.006.

6. Cho HS, Seo SH, Park SH, Park JH, Shin DS, Park IH. Minimal invasive surgery for unicameral bone cyst using demineralized bone matrix: a case series. BMCMusculoskelet Disord 2012;13:134. https://doi.org/10.1186/1471-2474-13134. 
7. Flores IL, Hamilton ME, Zanchin-Baldissera E, UchoaVasconcelos AC, Chaves-Tarquinio SB, Neutzling-Gomes AP. Simple and aneurysmal bone cyst: Aspects of jaw pseudocysts based on an experience of Brazilian pathology service during 53 years. Med Oral Patol Oral Cir Bucal 2017;22(1):e64-9.

8. Choi BJ, Choi SC, Kwon YD, Drew SJ. Aneurysmal bone cyst causing a pathologic fracture of the mandibular condyle. J Oral Maxillofac Surg 2011;69(12):2995-3000. https://doi.org/10.1016/j.joms.2010.10.058.

9. Martins-Filho PR, Santos Tde S, Araújo VL, Santos JS, Andrade ES, Silva LC. Traumatic bone cyst of the mandible: a review of 26 cases. Braz J Otorhinolaryngol 2012;78(2):16-21.

10. Cortell-Ballester I, Figueiredo R, Berini-Aytés L, GayEscoda C. Traumatic bone cyst: a retrospective study of 21 cases. Med Oral Patol Oral Cir Bucal 2009;14(5):e239-43.
11. Larheim TA, Westesson PL. Maxillofacial imaging. 2nd ed. Berlin: Springer; 2018. https://doi.org/10.1007/978-3-31953319-3.

12. Imanimoghaddam $M$, Javadian Langaroody $A$, Nemati $S$, Ataei Azimi S. Simple bone cyst of the mandible: report of two cases. Iran J Radiol 2011;8(1):43-6.

13. Fayzullina GA, Mirsaeva FZ, Urazbakhtin II. Method of treatment solitary bone cyst of the mandible [in Russian]. Meždunar naučno-issled ž 2016;49(7):101-3. https://doi. org/10.18454/IRJ.2016.49.066.

14. Nelson BL. Solitary bone cyst. Head Neck Pathol 2010;4(3):208-9. https://doi.org/10.1007/s12105-010-0179-1.

15. Suei Y, Taguchi A, Tanimoto K. Simple bone cyst of the jaws: evaluation of treatment outcome by review of 132 cases. J Oral Maxillofac Surg 2007;65(5):918-23. 